\title{
EFFECTS OF GROUND ROCKING ON DYNAMIC RESPONSE OF MULTISTORIED BUILDINGS DURING EARTHQUAKES
}

\author{
Vinay K. GUPTA* and Mihailo D. TRIFUNAC**
}

\begin{abstract}
This study investigates the consequences of neglecting the contributions of the rocking component in earthquake ground motions during response calculations of rigid base multistoried buildings. The buildings have been modeled by a simple shear-type lumped mass model and analyzed for several synthetically generated ground motions with varying characteristics. The expected values of the largest response peaks have been computed for the translational and for the rocking excitations, to evaluate the relative rocking contributions to the response. Those situations have been identified, in which the overall response is likely to receive significant contributions from the rocking component of ground motion.
\end{abstract}

Keywords : tail buildings, rocking, soft soil

\section{INTRODUCTION}

Dynamic response calculations of structures subjected to earthquake-induced base excitations are often simplified by ignoring the rocking component of ground motion ${ }^{15}$. This has been a widely accepted practice in the engineering community, largely caused by the lack of recorded strong motion accelerograms for this component. Though some efforts ${ }^{11,13)}$ have been devoted to measuring the ground rocking, at present, there exists no adequate experimental data for a meaningful statistical study of its nature. Satisfactory performance of many so designed buildings during most of the past earthquakes has contributed to the prevailing faith in this practice, as also reflected in the various design codes. The rocking component may, thus, be believed to add little to the overall building response, but there remains a need to substantiate this through detailed investigations. However, there exist a few special cases which, though occurring infrequently, will lead to large rocking contributions to the overall response.

Few studies ${ }^{1,2), 5,14)}$, which have so far been carried out to estimate the effects of the ground rocking, have emphasized the possible significance of the rocking in certain situations. Stratta and Griswold ${ }^{14)}$ studied the relative rotation between adjacent columns supporting a rigid slab and demonstrated the possibility of structural collapse in case of appreciable rocking. Ghafory-Ashtiany and Singh ${ }^{1)}$ found the effects of the rotational components to

\footnotetext{
* Assistant Prof. Civil Eng., I. I. T. Kanpur, 208 016, India

** Professor, Dept. of Civil Engineering, University of Southern California, Los Angeles, California, 900892531, USA
}

be significant and dependent on building height, plan dimensions and the shear wave velocity in the soil. Gupta and Trifunac ${ }^{2}$ showed that the rocking contributions to fixed-base buildings are larger on soft soils and increase with the rise in story-height. Their results have been based on realistic modeling of the rocking excitation which accounts for the effects of dispersion and transient arrivals of waves, and the presence of different modes in the propagating waves. This model has been developed by Lee and Trifunac ${ }^{7}$ to generate the synthetic rocking accelerograms and it is based on earlier results ${ }^{16)}$ using the theory of wave propagation in elastic layered medium. Other investigators have simplified the representation of the rocking excitation by assuming horizontally travelling monochromatic shear waves with constant shapes and velocities.

Though the results of Gupta and Trifunac ${ }^{2)}$ add significantly to understanding of the rocking contributions, their results are on the conservative side since the translational and rocking components have been assumed to act in phase with each other. Trifunac $^{17)}$ and Lee and Trifunac ${ }^{7)}$ showed that the rocking and translational components of strong ground motion associated with incident plane $\mathbf{P}$ and SVwaves, and Rayleigh surface waves differ in phase by $\pi / 2$ for all the frequencies. In actual ground conditions, the phase may vary with frequency, having fluctuations about this value, and therefore, the level of rocking contributions may be somewhat less than that projected in the simplified analysis of Gupta and Trifunac ${ }^{2}$. Further, approximating the variation of rocking-totranslational amplitude ratio, on log-log scale, by a straight line joining the high and low frequency amplitudes [see References 2) and 7)] fails to repesent the details of rocking motion peaks, which 


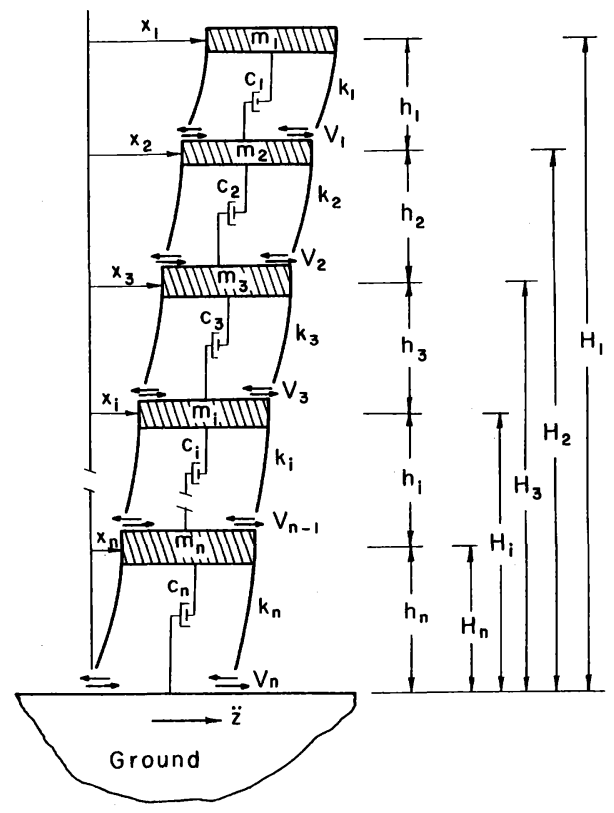

Fig.1 Multi-Degree-of-Freedom System for Translational Vibrations.

may not actually occur exactly at those periods which correspond to the translational peaks. This shortcoming in the straight line approximation ${ }^{6), 7}$ can become crucial especially for the periods in the intermediate range $(0.1-4 \mathrm{sec})$ where most structures have their natural periods. Thus, further investigation is required for more detailed information on the increase in lateral seismic forces due to the rocking component of ground shaking.

This study offers a more detailed treatment of the problem in an effort to establish greater confidence in the prevalent practice of ignoring the rocking component when its contributions are small, and to identify those earthquake excitations, site and structure combinations which may require appropriate allowances in the seismic loads for this component. For the purpose of analysis, a probabilistic approach ${ }^{3,4)}$ based on the response spectrum superposition method has been employed.This approach had been suggested for the fixed-base multistoried buildings subjected to translational and rocking components of ground motion and it adequately accounts for the effects of the phase difference between these two components. The accelerograms and Fourier spectra required to represent the earthquake excitations have been generated synthetically ${ }^{7)}$ for a few chosen sites. Results have been obtained for the "expected" values of the largest response peak amplitudes, to give an "average" idea, in quantitative terms, of the extent of magnification resulting from the
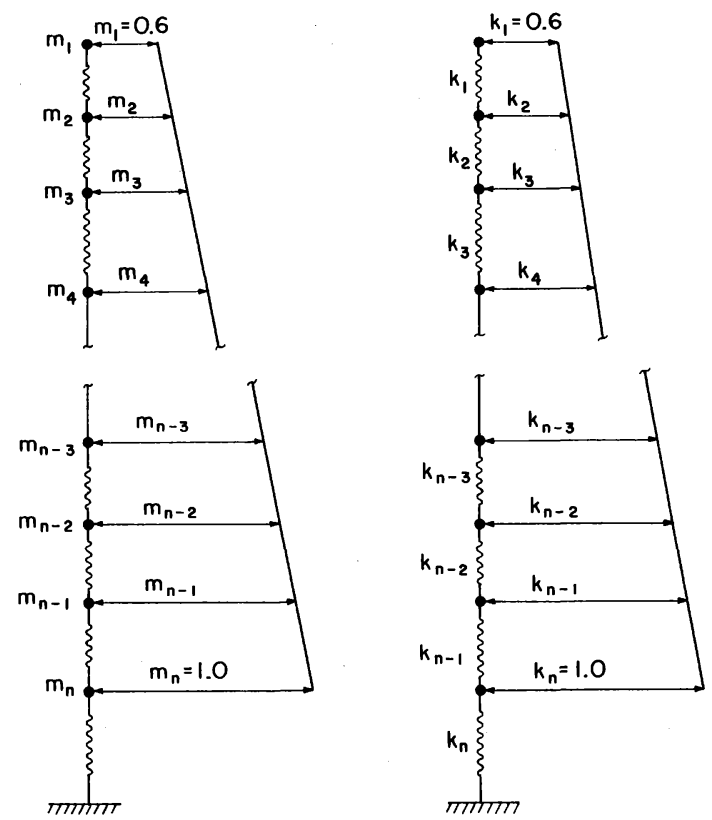

$m_{j}=1.0-0.4 \frac{n-j}{n-1}$

$j=1,2, \cdots, n$

$$
\begin{array}{r}
k_{j}=1.0-0.4 \frac{n-j}{n-1} \\
j=1,2, \cdots, n
\end{array}
$$

Fig.2 Story Stiffnesses and Floor Masses in a $n$-Story Building.

presence of rocking in the ground motion.

\section{EXAMPLE BUILDING AND EARTHQUAKE SITES}

Responses of 19 Fixed-lower case : base multistoried buildings (modeled as in Fig.1), with number of stories varying from 2 to 20 , have been studied here for various sets of parameters. In each building, the variation of floor masses and story stiffness values from top to bottom is as illustrated in Fig.2, with their relative values so proportioned that the fundamental period of vibration of each building is 0.1 times the number of stories ; the height of each story is $5.0 \mathrm{~m}$; and the critical damping ratio is 0.05 in all the modes of vibration (for the 10 storied building the natural frequencies in $(\mathrm{rad} / \mathrm{sec})$ in translational vibrations are 6.01, $16.19,26.32,35.92,44.74,52.57,59.23,64.58$, 68.49 , and 70.89 , while for the 20 story building, they are $2.98,8.12,13.36,18.55,23.63,28.59$, $33.37,37.39,42.34,46.46,50.31,53.87,57.11$, $60.01,62.57,64.75,66.56,67.98,69.00$ and 69.62 ). Each building has been analyzed first for the translational component of ground motion and then, for the combined action of translational and rocking components. The phase difference between the translational and rocking components of ground motion (assumed to be independent of 


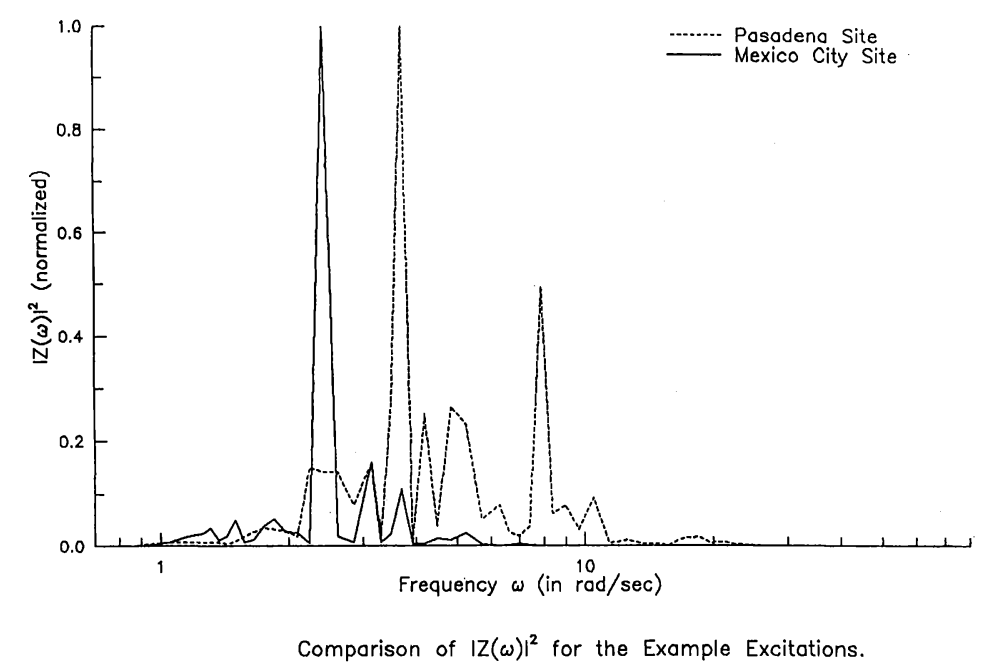

Fig.3 Normalized Amplitudes (squared) of Fourier Spectra of Horizontal Motion $(Z(\omega))$ for Pasadena and Mexico City Sites.

frequency ${ }^{3,4)}$ ) has been uniformly taken as $\pi / 2$ for all the example excitations ${ }^{7,177}$.

Records of the translational and rocking excitations have been generated ${ }^{7}$ for i ) Mexico City, Mexico (Fig.3), ii ) Milikan Library, Pasadena, California (Fig.3), iii) 445 Figueroa Street, Los Angeles, California, and iv) Hollywood Storage Building, Hollywood, California sites ${ }^{3}$. At the Mexico City site, two identical soil models with five layers (including the half-space) but having different shear wave velocities in the top layer have been considered. The shear velocity in one of these is $40 \mathrm{~m} / \mathrm{sec}$, whereas it is $80 \mathrm{~m} / \mathrm{s}$ in the other model. Soil models for the Pasadena, Los Angeles and Hollywood sites, respectively, have 8, 9 and 6 layers with shear velocity in the top layer equal to 185,365 and $230 \mathrm{~m} / \mathrm{sec}$. Further details about these strata may be found in Reference 3 ). The soil data has been utilized to compute the dispersion curves of surface waves and thus obtain the group and phase velocities of these waves in various modes and frequencies.

Synthetic records for the Mexico City sites have been based on the recorded spectrum for the horizontal component during the 1985 earthquake (taken as the input Fourier amplitude spectrum, Fig.3) whereas those for the Pasadena (Fig.3) and Hollywood sites correspond ${ }^{20)}$ to the recorded horizontal components in Borrego Mountain,California earthquake of 1968. The epicentral distances are taken as 10, 60 and $40 \mathrm{~km}$ for the Mexico City, Pasadena and Hollywood sites. These are less than the actual distances of the sites to the respective epicenters of the earthquakes $(400,220$ and 240 $\mathrm{km}$ ) since the wave dispersion computed for a given site soil stratum is not applicable for the entire epicentral distance, following the variations in geology of the area over such large distances. If the actual epicentral distance itself is smaller, no such modifications may be required ${ }^{3)}$. In addition to the actual recorded motions, synthetic records ${ }^{7,18,19)}$ have also been generated for hypothetical earthquakes of varying magnitudes $(5.5,6.5,7.5$ and 8.5) on the San Andreas fault, for the Los Angeles, Pasadena and Hollywood sites. For this, the epicentral distances are taken as 50,40 and $50 \mathrm{~km}$ respectively based on the actual distances to the closest locations on the fault. The input Fourier amplitudes for these earthquakes are estimated on the basis of statistical study of a large collection of past earthquake records ${ }^{18)}$.

\section{RESULTS AND DISCUSSION}

Each of the 19 buildings as described in section 2 has been analyzed first for the translational component of ground motion and then, for the combined translational and rocking excitations. For a building, the expected values of the peak amplitudes have been computed for the first order peaks of displacement, shear force and overturning moment at each floor and, then, for each of these response functions, the magnification factors $\Gamma_{i}, i=1,2, \ldots n$ (due to rocking) have been calculated by taking the ratio of the peak values for translational plus rocking excitation to those for the translational excitation alone. It has been observed that the variation of $\Gamma_{i}$ with story level $i$ is small and therefore, for each of the 19 buildings, magnification factors $\Gamma$ for the three response functions have been obtained by averaging the corresponding $\Gamma_{i}$ 's 


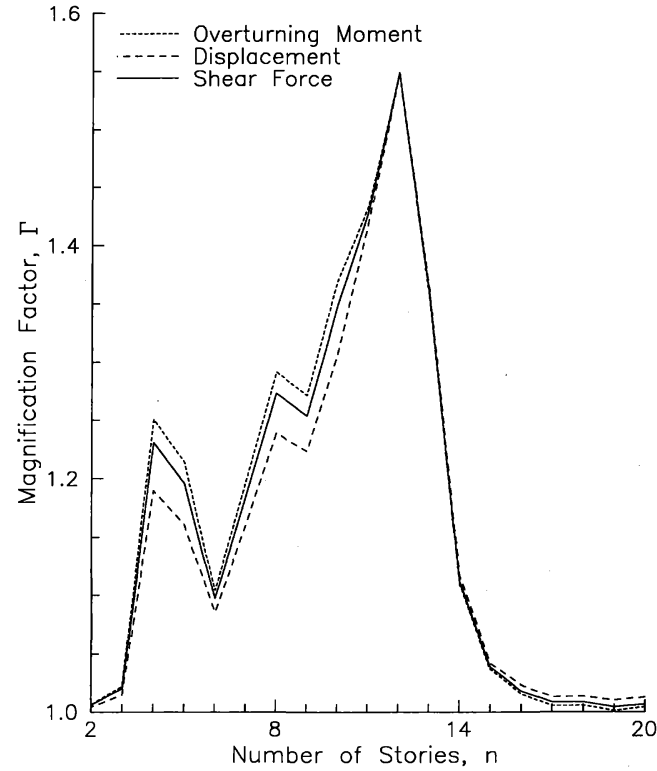

Fig.4 Magnification of Different Response Functions due to Rocking at Mexico City Site.

using the relation $\Gamma=\frac{1}{n} \sum_{i=1}^{\mathrm{n}} \Gamma_{i}$. These results have then been represented by the plots showing the variation of the magnification factor $\Gamma$ with the total number of stories, $n$. For each earthquake excitation, there are three plots corresponding to displacement, shear force and overturning moment and therefore, each of these can serve as a basis for study of the effects of various parameters on the magnification factors for different buildings. However, the results have shown little difference between the plots for the three response functions. This has been illustrated here in Fig.4 for the Mexico City site with $40 \mathrm{~m} / \mathrm{sec}$ shear wave velocity in the top soil layer. Therefore, all the subsequent results are presented considering only the displacement as a response function.

Following is the discussion on the effects of various input parameters on the magnification factors $\Gamma$ :

\section{(1) Story height}

All the 19 buildings have been analyzed for constant story heights of $3 \mathrm{~m}, 4 \mathrm{~m}$ and $5 \mathrm{~m}$. Results are presented for the same Mexico City site as in Fig.5. It is seen that the effect of rocking increases with an increase in the story height, the other factors remaining unchanged. This follows from the definition of the modal participation factor for rocking ${ }^{3,4)}$, since this factor proportionately rises with the increase in story height. The maximum increase in percentage of rocking contribution for this example is in the case of a 12-story building.

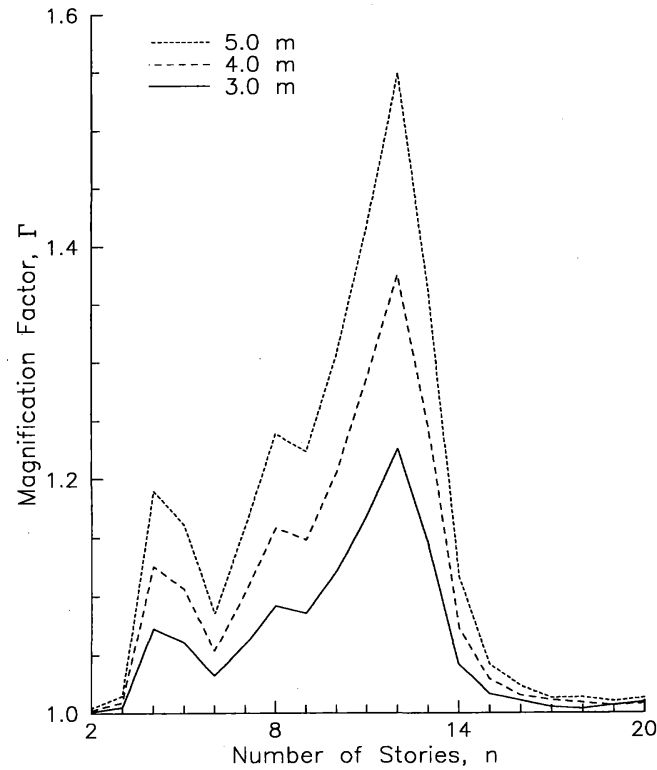

Fig.5 Effect of Story Height on Rocking Contributions at Mexico City Site.

\section{(2) Minimum shear wave velocity}

The ratios of rotational to translational spectra at low and high frequencies, respectively, are inversely proportional to the maximum and minimum shear wave velocities in the soil stratum ${ }^{6,7)}, \beta_{\max }$ and $\beta_{\min }$. Since $\beta_{\min }$ usually corresponds to the top layer of stratum which is likely to have some local variations, it may be worthwhile to study the effects of variation in $\beta_{\min }$ on the rocking contributions to the overall response. For this purpose, the sites at Mexico City have been considered, with $\beta_{\min }=40$ and $80 \mathrm{~m} / \mathrm{sec}$ for the two example models and for the same excitation (Fig.3). Fig.6 shows plots of the magnification factor $\Gamma$ with the number of stories $n$ for these two cases. It is observed that the increased value of $\beta_{\min }$ results in lesser contribution of rocking, implying that softer ground conditions lead to relatively higher amplitudes in the rocking spectrum. It is also noted that the amplification resulting from the soft ground conditions follows different patterns for the different shear wave velocities in the top layer. For $40 \mathrm{~m} / \mathrm{sec}$ shear wave velocity, a 12 -story building shows the maximum rocking contribution, while in the case of $80 \mathrm{~m} / \mathrm{sec}$ velocity, an 8 -story building experiences the maximum contribution from rocking. This suggests that, at different sites having different shear wave velocities in the top layer, buildings with different number of stories experience the maximum contribution of rocking and, as the shear wave velocity increases, the natural period of vibration of such buildings (those having maximum contribution 


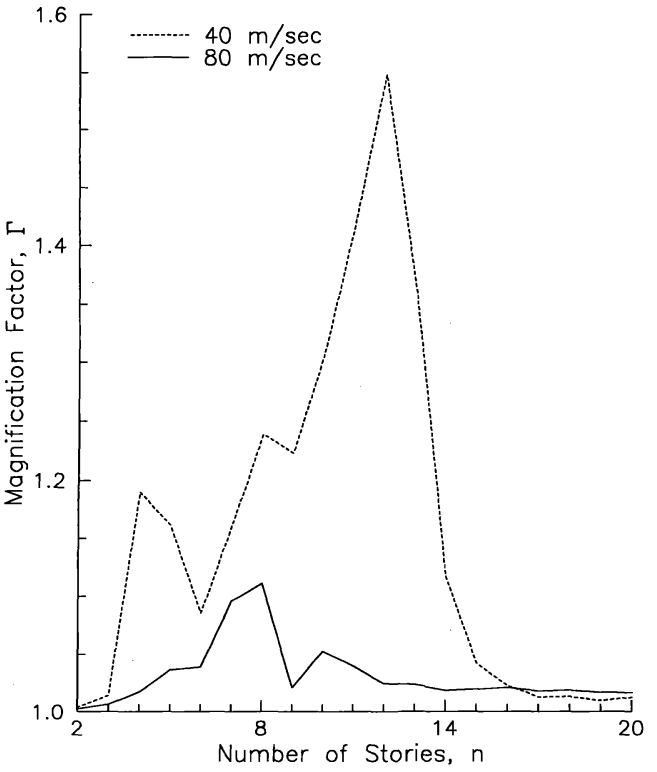

Fig.6 Effect of $\beta_{\min }$ on Rocking Contributions at Mexico City Site.

from rocking) decreases.

\section{(3) Earthquake magnitude}

Earthquakes of higher magnitude have larger Fourier amplitudes in the longer periods ${ }^{18)}$ and it is possible that the resulting different energy distribution among various frequencies might affect the relative rocking contributions to the response. To investigate this, four different sets of synthetic records have been considered at the Pasadena site for magnitudes $5.5,6.5,7.5$ and 8.5 and the results on the variation of the magnification factor $\Gamma$ are shown in Fig.7. It can be observed that the effect of rocking on the structural response is hardly affected by the change in magnitude. This shows that the relative significance of ground rocking contributing to the structural response comes from presence of prominent peaks in the Fourier spectra of ground motion and not from the overall spectrum amplitudes.

\section{(4) Concentration of energy in long period waves}

Comparison $^{3,6,7)}$ of various translational spectra with the corresponding rocking spectra shows that high energy peaks of the translational spectra tend to shift to the shorter periods in the rocking spectra. In typical translational spectra, high energy peaks are usually in the range of $0.2-0.4 \mathrm{sec}$, resulting in high energy peaks in the rotational spectra at periods less than $0.2 \mathrm{sec}$. These periods are short in comparison with fundamental periods of the typical multistoried buildings. Thus, the buildings are likely to "miss" the high energy peaks

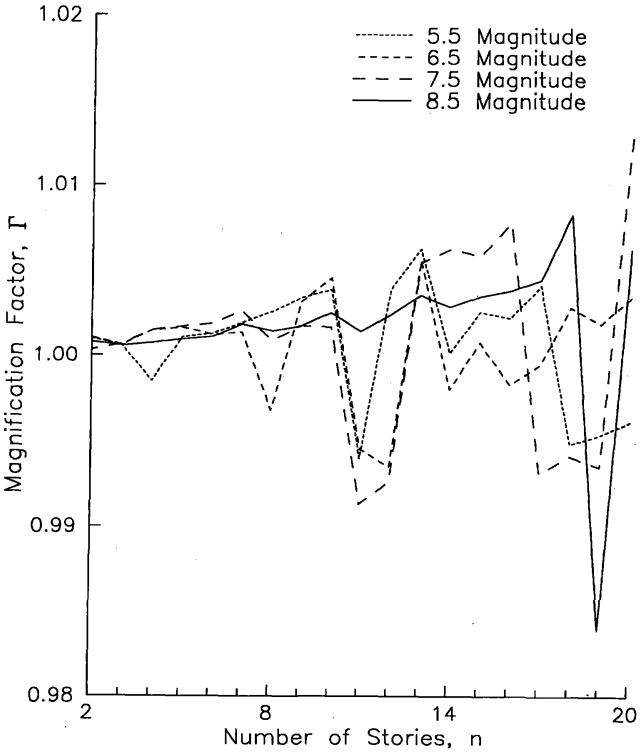

Fig.7 Effect of Earthquake Magnitude on Rocking Contributions at Pasadena Site.

of the rocking motion and, thus, have less contribution from the rocking ground motion. However, if the translational spectra have high energy peaks in 1-3 sec range, one can expect the rocking spectra to have high energy peaks at periods longer than 0.2 sec. This should result in relatively larger contributions of rocking for some multistoried buildings. The cases of energy concentration in the long period waves are usually observed when the sourcesite distances are large $\mathrm{e}^{20)}$.

To study this aspect, the sites at Hollywood and Pasadena are considered for a hypothetical earthquake along San Andreas fault (6.5 magnitude) and for the Borrego Mountain earthquake, 1968. The Fourier spectra of the recorded translational motion at these sites for the latter have exhibited large peaks at long periods ${ }^{20}$. The values of the magnification factor $\Gamma$ have been computed and compared for all the 19 buildings for these two earthquakes. It can be observed in Figs. 8 and 9 that, for most buildings, Borrego Mountain earthquake results in somewhat greater contribution of rocking as compared to the hypothesized earthquake of similar magnitude along San Andreas fault. Since the same dispersion curves have been used in the development of accelerograms for the Borrego Mountain earthquake as for the hypothetical event along San Andreas fault, it is apparent that the noted changes in rocking contributions result from the concentration of incoming energy in the longer periods. Thus an unusually high magnification observed in the case 


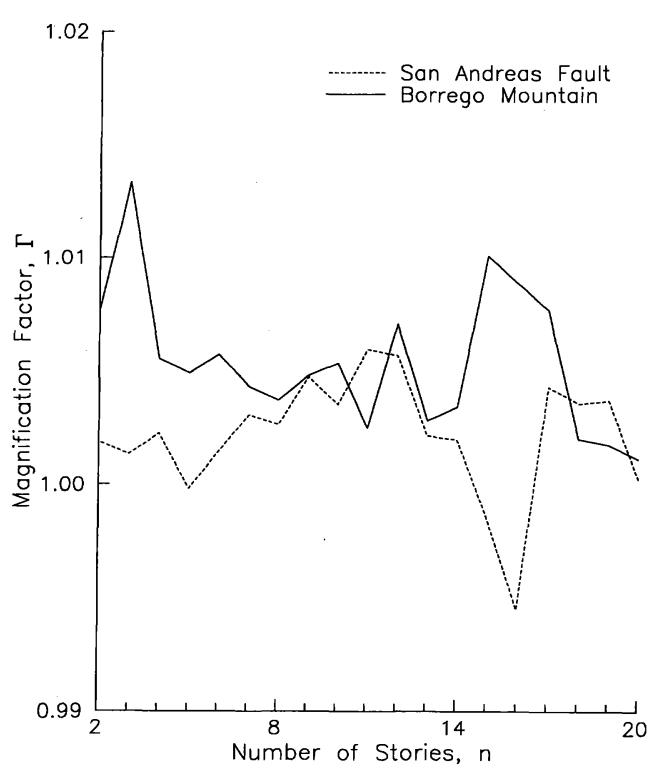

Fig.8 Effect of Concentration of Energy in Long Period Waves on Rocking Contributions at Hollywood Site.

of Mexico City site due to rocking may be attributed to the fact that energy was concentrated in long period waves.

Concentration of energy in long period waves is thus important for the typical multistoried buildings, but in case of the structures having lower periods of vibration, rocking contributions may still turn out to be significant even when the seismic energy is well distributed in various periods. This can be illustrated by considering, for example, a case of buildings having natural periods of vibration as 0.05 times the total number of stories, $n$. All the 19 example buildings have been reconsidered and their mass and stiffness values reproportioned suitably (for the new lower natural periods) while retaining the variation of floor masses and story stiffnesses. Magnification factors have been recalculated for all these buildings under the excitation (6.5 magnitude) at the Los Angeles site and compared (see Fig.10) with those obtained for the same buildings assuming the periods as $0.1 n$. It may be observed that even though the energy is distributed over a wide range of frequencies including the high frequencies, the rocking contributions could increase slightly for all of the buildings.

The above results agree qualitatively with those of Gupta and Trifunac ${ }^{2}$, but there exists a difference in the order of the relative rocking contributions. Gupta and Trifunac ${ }^{2}$ combined the individual translational and rocking contributions linearly assuming zero phase difference which appears

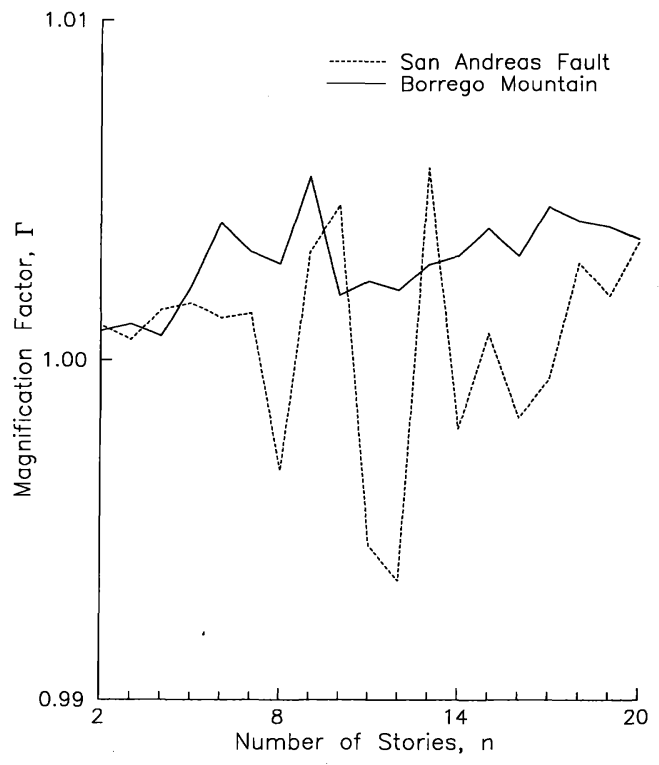

Fig.9 Effect of Concentration of Energy in Long Period Waves on Rocking Contributions at Pasadena Site.

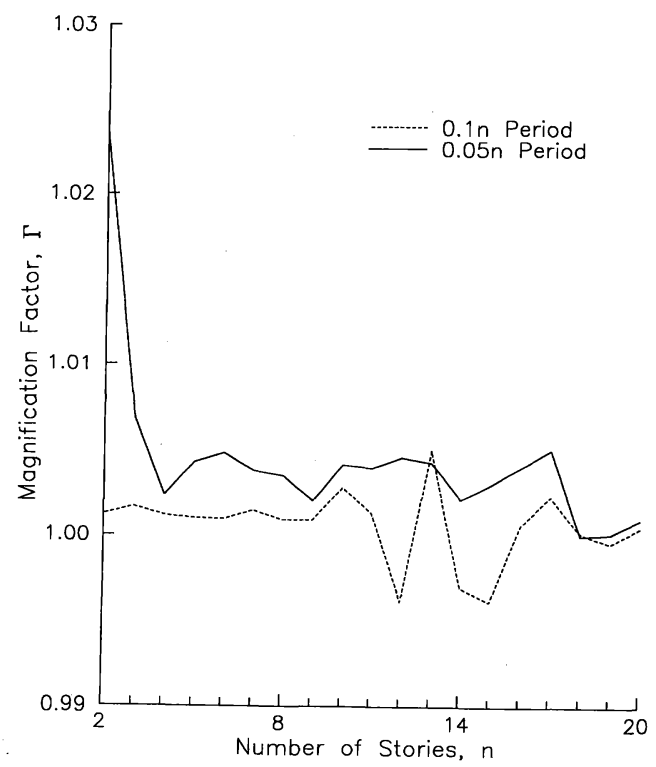

Fig.10 Effect of Reducing Natural Periods of Buildings at Los Angeles Site.

to have overemphasized the rocking contributions in their calculations. On the other hand they did not consider the Mexico City type situation which has been shown here to be associated with substantial rocking contributions.

\section{CONCLUSIONS}

An investigation has been carried out to explore selected situations in which the underestimation of 
design forces in multistoried buildings due to neglecting the rocking component of ground shaking may be critical for the safety of the buildings. Using simple lumped mass model and a probabilistic approach to compute the expected values of the first peaks of the displacement at various levels of a building, additional displacements caused by the rocking component as a fraction of the contributions of the translational component have been computed. Several example sites and buildings with varying natural periods of vibration have been considered. The following conclusions can be made :

(1) Increasing story heights of the buildings leads to greater rocking contribution to the overall response.

(2) The buildings situated on softer grounds and/or subjected to earthquakes with most of the energy carried by the long period waves may be prone to larger contributions from the rocking component of ground motion. In case of the Mexico City site where the buildings are situated on soft soil and also, where there was large energy concentration during the 1985 earthquake at relatively long periods, near 2.5 seconds, the additional contributions from rocking have been found to be large for buildings 8-13 stories high. Some post-earthquake damage reports ${ }^{8) \sim 10}$ have indicated that most of the buildings damaged were those of intermediate heights having 7-15 stories. Particularly in the case of steel buildings, 59 out of 102 damaged buildings had 7-16 stories. As per the survey ${ }^{12}$ made in Cuauhtemoc district which was the most serverely affected area by the earthquake, $\sim 37 \%$ of the buildings having 9-12 stories were damaged during earthquake as compared to $\sim 3 \%$ and $-36 \%$ of the buildings respectively with $<9$ stories and $>12$ stories. These observations appear to be in agreement with the results of this study and hence, it is possible that in Mexico City during the 1985 earthquake, many buildings might have suffered significantly as they were not designed to withstand the additional contributions of rocking to the lateral seismic forces. For the examples considered in the Los Angeles area, it has been seen that the concentration of energy in long period waves does lead to additional rocking contributions, but that those do not seem large enough to cause much concern. However, if a particular site in Los Angeles area has very soft soil conditions, it may be necessary to include the effects of rocking component in response calculations there.

(3) Magnitude of the earthquake has negligible effect on the relative rocking contributions.

(4) Stiff structures, e.g. nuclear power plants with short periods of vibration may be subjected to greater contributions of rocking in typical earthquake excitations and these may become substantially large in soft soils. Detailed investigations are, however, required to substantiate this preliminary observation.

Above conclusions are based on the assumption that there is no soil-structure interaction. For buildings situated on flexible foundations, modification of the free-field motion spectra in terms of the energy distribution, and amplifications in the base rocking may present new conclusions for the sites having medium soil conditions. Further investigations are thus required to quantify the effects of ground rocking in that case.

\section{REFERENCES}

1) Ghafory-Ashtiany, M. and Singh, M.P.:Structural response for six correlated earthquake components, Earthq. Eng. Struct. Dyn. 14, pp.103 119, 1986.

2) Gupta, I. D. and Trifunac, M. D.:A note on contribution of rocking excitation to earthquake response of simple buildings, Bull. Ind. Soc. Earthq. Tech. 25 (2), pp.73 89, 1988.

3) Gupta, V.K. and Trifunac, M. D.:Investigation of building response to translational and rotational earthquake excitations, Report CE 89-02, University of Southern California, Los Angeles, California, 1989.

4) Gupta, V.K. and Trifunac, M. D.:Response of multistoried buildings to ground translation and rocking during earthquakes, J. Prob. Eng. Mech. Vol.5, No.3, pp.138 $145,1990$.

5) Koh, A.S. and Spanos, P.-T. D.:Seismically induced rocking of rigid structures, Proc. Eighth Wld. Conf. Earthq. Eng., San Francisco, California, IV, pp.251 258, 1984.

6) Lee, V.W. and Trifunac, M.D.:Torsional accelerograms, Soil Dyn. Earthq. Eng. 4 (3), pp.132 139, 1985.

7) Lee, V.W. and Trifunac, M. D.:Rocking strong earthquake acceleration, Soil Dyn. Earthq. Eng. 6 (2), pp.75 89, 1987.

8) Martinez-Romero, E.:Damage assessment and seismic behavior of steel buildings in Mexico City, Proc. Int. Conf. Mexico Earthquake-1985, Published by ASCE, 1985.

9) Meli, R. and Avila, J.A.:The Mexico earthquake of Sept. 19, 1985-analysis of building response, Earthq. Spectra 5 (1), pp.1 17, 1989.

10) Miranda, E. and Bertero, V.V.:The Mexico earthquake of September 19, 1985-performance of low-rise buildings in Mexico City, Earthq. Spectra 5 (1), pp.121 143, 1989.

11) Niazi, M.:Inferred displacements, velocities and rotations of a long rigid foundation located at El-Centro differential array site during the 1979 Imperial Valley, California earthquake, Earthq. Eng. Struct. Dyn. 14, pp.531 542, 1987.

12) Norena, F., Castaneda, C. and Iglesias, J.:The Mexico earthquake of Sept. 19, 1985-evaluation of the seismic 
capacity of buildings in Mexico City, Earthq. Spectra 5 (1), pp.19 24, 1989.

13) Oliveira, C.S. and Bolt, B. A.:Rotational components of surface strong ground motion, Earthq. Eng. Struct. Dyn. 18, pp.517 526, 1989.

14) Stratta, J.L. and Griswold, T.F.:Rotation of footing due to surface waves, Bull. Seism. Soc. Amer. 66, pp.105 108, 1976.

15) Todorovska, M.I. and Trifunac, M.D.:A note on excitation of long structures by ground waves, ASCE, EMD Vol.116, No.4, pp.952 964, 1990.

16) Trifunac, M.D.:A method for synthesizing realistic strong ground motion, Bull. Seism. Soc. Amer. 61, pp.1739 1753, 1971.

17) Trifunac, M.D.:A note on rotational components of earthquake motions on ground surface for incident body waves, Soil Dyn. Earthq. Eng. 1 (1), pp.11 19, 1982.

18) Trifunac, M.D.:Dependence of Fourier spectrum amplitudes of recorded strong earthquake accelerations in terms of magnitude and local soil and geologic conditions, Earthq. Eng. Struct. Dyn. 18, pp.999 1016, 1989.

19) Trifunac, M.D.:How to model Amplification of Strong Earthquake Motions by Local Soil and Geologic Site Conditions, Int. J. Earthquake Eng. and Structural Dynamics, 19 (6), pp.833 846, 1990.

20) Trifunac, M.D. and Udwadia, F.E.:Variations of strong earthquake ground shaking in the Los Angeles area, Bull. Seism. Soc. Amer. 64 (5), pp.1429 1454, 1974.

(Received April 24, 1990) 